\title{
Book Review: A Column of Cloud and a Column of Fire: Dimitris Lyacos' Poena Damni
}

\author{
Robert Zaller (Corresponding author) \\ Drexel University, USA \\ Email: zallerrm@drexel.edu
}

Received: 07/07/2020

Accepted: 10/08/2020

Published: 01/09/2020

Volume: 1 Issue: 3

How to cite this paper: Zaller, R. (2020). Book review: A Column of Cloud and a Column of Fire: Dimitris Lyacos’ Poena Damni. Journal of Critical Studies in Language and Literature, $1(3), 70-76$

DOI: https://doi.org/10.46809/jcsll.v1i3.30

Copyright (C) 2020 by author(s) and Global Talent Academy Ltd. This work is licensed under the Creative Commons Attribution International License (CC BY 4.0).

http://creativecommons.org/licenses/by/4.0/

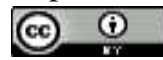

One of the most original and significant texts to have come out of Europe in the past generation is Dimitris Lyacos' poetic trilogy, Poena Damni. I call it "poetic" because there is no word that quite describes a work that moves alternately between poetry, prose, and drama, and that turns each like a prism in a quest for meaning that yields no final stability but only a "further horizon of pain" (The First Death, Section X).

As the above suggests, the text offers us a shifting series of scenes and perspectives, somewhere between a journey and a travail. There is an implicit narrative voice, but no narrative, that shifts abruptly from first to third person, a thread of consciousness that weaves in and out of dream and waking, fantasy and vision, confronting us at every turn with that which both forces and repels our sight. You know there is a narrative, because something in the voice compels you to continue; you simply do not know what is being told. You are simply within the framework of a temporality in its most radical sense.

Dimitris Lyacos was born in Athens in 1966, and studied law and philosophy. It was conceived back to front, with its "last" part, The First Death, written and published first, and the other segments proceeding backwards toward an origin that instates the original wound of the poem's birth. Lyacos has revised it extensively over the course of some thirty years, retracting an earlier version of what is now With the People From the Bridge that was originally published as Nyctivoe and heavily revising the text called Z213: EXIT. The suggestion, I think, is clear: the poem remains open, a circularity that deflects all progression, an ourobouros that never meets its own tail.

How to begin, then, with a text of this nature? Perhaps we might start with the act of writing itself. Nearly midway through the revised text of the middle volume of the poem, Z213: EXIT, a prose section begins thusly:

Make a point of remembering to write as much as I can. As much as I remember. In order for me to remember. As I keep writing I go into it again. Afterwards it is as if it were not I. How do I know that I have written this. Faded, someone else's words. My own handwriting though. From a void I wake up within, time after time. . . (Z213: EXIT, p. 61)

The voice of this section has no identity, most of all for itself. It begins in the fashion of a diary injunction to get something important down, indeed something crucially vital. No subject is specified, however, other than the act of remembering itself, of remembering in order to have memory. The writing must not stop, has no point at which it can safely stop, and yet its 
continuity as an act does not guarantee the writing subject. Repetition ("I go into it again") is no foothold either, for as soon as there is a halt or a pause, everything is lost: "Afterwards it is as if it were not I." The effacing hand is temporality itself, for no sooner does the pause introduce it then everything instantly 'fades,' and the words, even if still physically present, belong to someone else, an identity not one's own. The speaker may even recognize his own handwriting, but only as a piece of external evidence suppositionally linked to but already alienated from himself. The attempt to create memory by marking time collapses upon itself, and, returned to a pre-maternal void in which the speaker wakes without birth to find himself in a "within," he can only labor without issue, "time after time."

The reader will recognize in this passage an echo of Samuel Beckett's The Unnamable, with its futile attempt to create a past by moving forward ("I can't go on. I'll go on"), and the temporal abrogation of Pozzo's climactic speech in Waiting for Godot: "They give birth astride of a grave, the light gleams an instant, then it's night once more." We might not need to hear this again, especially expressed as inimitably as it was the first time; but Lyacos' perspective is quite different. The real precursor of his poem is the Odyssey, by way of the New and Hebrew Testaments and such modern texts as George Seferis' "The Argonauts." Superficial resemblance notwithstanding, it is not as in much of Beckett a journey to the interior of the self, with or without a mirroring companion, but outwards toward a community of others.

We must, therefore, correct ourselves at the outset: if the problem of the self is identified with memory in the passage we have cited, Lyacos lays claim to the collective temporal dimension we inhabit as well, that of history. To put it in terms of the texts he appropriates for his vision, if the Odyssey is a circular journey that returns to its point of origin-the arc never quite completed in his own poem - the Bible, taken in both its books, is a long passage toward a transcendence that, always immanent, remains frustratingly out of reach. The condition this presents for the modern subject, with the burden of a situation that portends the end of the human story not as transcendence but annihilation, is the presiding subject of Poena Damni.

We might, then, seek another point of entry into the text (and many might be chosen, given its aspect of circularity). The first of the fourteen sections that comprise The First Death is a prose passage that describes a broken piece of human flotsam in a condition of ultimate extremity:

Sea of iron. Moon silent as pain in the depth of the mind. A body swept here and there on the rocks like seaweed or a lifeless tentacle, fruit of a womb ship-wrecked by the winds, ensanguined and flesh-filled mire. The left arm cut short, the right to the end of the forearm, a rotted stick raving amid the water's lungs. Of the ravaged mouth there remained only a wound which closed slowly. From the eyes a blurred light. The eyes without lids. The legs down to the ankles - no feet. Spasms. (The First Death, p. 9)

The Odyssey is invoked here, the peril known to every sailor. It is not clear whether the broken body is alive or dead, or perhaps better said capable of death. It is moved as if "lifeless," but also "raving," shaken by spasms, and with a wound still 'closing.' Seemingly rejected by a "Sea of iron," it also appears to drown in a watery lung under a moon whose silence suggests a pain too deeply embedded for expression. If in our first-quoted passage a balked narrator seeks an identity that continually eludes his grasp, in this one, it is a core of suffering that cannot relinquish itself.

This scene would seem to be the reductio ad nihilo of the human predicament, a thrashing agony indifferently trundled among shape-shifting elements. Nonetheless, a consciousness slowly emerges in subsequent sections of the poem, prodded by an authorial persona that suggests both the possibility of will ("Keep moving") and the intuition of a shared destiny ("aware that all men have drowned within you," 15). These are not merely the companions of the subject's own suppositional journey - the shipwreck of a particular Ithaca — but of all deaths in all places: "regiments of the dead whispering unceasingly / in a limitless graveyard" (13). This suggests in turn the mythic sacrifice of a Year God, "the return / of a dismembered body in the spring" (12), and the terrain of a more familiar religious imagery, "the heavenly hand which now / draws you with all its might" (15). But salvation - if that is what is on offer-is not so easily obtained from a source that is itself perhaps not so easily what it seems:

Consequence of a face without mouth. Thirst for resurrection. I am baptized in the trenches of mourning; dry kisses, bitter sponge, the rotted leaf returning to the ground. Turn back inside. I swell with lust, unhallowed I writhe, in the recesses of your body I spill my blood. (p.16)

This complex and twisting passage returns us to the beginning of The First Death, with its image of a mouth that is simply a wound closing on its own silence. The mouth, and the broken body to which it is attached, "thirsts" for something that is for the first time identified as "resurrection." Has the body died, or is it simply wandering among the "regiments of the dead" in the state that lies between death and extinction, and in which it conceives the desire-or premonition-of resurrection? The passage shifts from third to first person, with a subject introduced in mid-sentence. The voice we hear declares itself to be "baptized," thus completing the conventional circuit of Christian imagery, but it is so only among the dead or at least those in uncertain transit, receiving the ministrations of dry kisses and a bitter sponge on a body itself defined as in an irreversible process of decay. The "life" this brings it to is similarly grotesque; it swells with lust as though merely proceeding to a further state of corruption, and it 'writhes' with this in a motion indistinguishable from pain. It is, in a word, "unhallowed"; 
that is, uninhabited by a truly animating spirit, and perhaps being taken only to a further level of darkness in which (as Lyacos sets the scene), there is only 'scourging,' 'slaughter,' and the image of a now-screaming moon.

At this moment, the speaking subject again changes register and identity: "in the recesses of your body I spill my blood." This seems, unmistakably, the voice or at least the gesture of a savior-figure, sacrificing its own blood for the tortured body. The result, however, is only further degradation that, in the poem's next section, "surfeited with pain / . . / will overflow / and spit all out / and drink it all, once more // to reach / the dregs of scream" (p. 17). This passage, too, plays on contradiction, for what seems an ultimate cry of agony from the furthest recesses of pain, is nonetheless an affirmation that suggests, again, the "heavenly hand" of Section IV that "draws ... with all its might."

The reigning image here seems to be that of Christ's own sojourn in hell, which is both a "harrowing" of wickedness and a voluntary immersion in it. Incorruptible, Christ cannot experience hell as the damned do; he is sovereign over it. At the same time, however, he has taken upon himself all sin and punishment as the Man of Sorrows, and so the sojourn in hell is a completion of the arc of salvation, an extension of it to the land of the dead. In Christ, this arc is perfect and foretold; nothing further remains to be accomplished by divinity alone. But it is only here that the human story properly begins.

II

If we recall the tripartite structure of Lyacos' poem, and likewise of its major sources, we can see the conundrum The First Death seems to pose in better context. The world of the Odyssey knows no heaven, but it is framed by an underworld to which Odysseus can gain access only by drinking from a blood-pit. The connection between the world of the living and that of the dead is, consequently, one in which the vital source is also connected to ritual pollution and contamination. The intercourse between the two realms is fraught with peril; in effect, it is a wager of mortality. Redemption is not part of this equation; only the hero attracts the attention of the gods, in many cases fatally: hence the phenomenon of tragedy. The broken being to whom Lyacos introduces us at the beginning of The First Death and who moves through a terrain of the dead to a space suspended between a beseeched heaven and an apparent hell is thus pre- as well as perhaps post-Christian, a circling between hope and despair in which faith remains out of reach. The only thing clear is that the First Death's subject cannot achieve "resurrection" for himself alone, and that the effort to do so evokes only a deity that intensifies his predicament, filling him with the spurious vitality of a lust whose contortions assume the aspect of agony.

We are thus presented with the necessity of the Other. The bridge that leads the subject toward his counterpart begins, paradoxically, with that very lust that denies him the status of anything but an object. In Christian terms, lust is sin, but outside them it is as Freud, the still-presiding figure of our own age, describes it, an instinctual drive that seeks merely a locus of discharge. Human relations, then, begin with an act that simultaneously establishes and denies them.

For Lyacos, sexuality is a point of origin - always, as in the poem's motion of circularity, to begin again and again -in which the self and the other are constituted simultaneously. Again, we may choose a passage that expresses this with particular clarity, from Z213. It begins with a baffled subject who has been "walking for long without purpose." He does not know where he has come from or where he is going, nor can he recall his name although he supposes he must have one. He instructs himself — or is instructed - to "Sit," and at the same time to try something again that he fears will not (cannot?) be accomplished.

This introduction segues without pause to a room in which the subject recognizes a woman who has been an object of desire. It is a contemporary scene; there is a furnished room which voices penetrate from outside, and desire enacts itself in the form of a passive submission to a bodily event:

I laid with my legs stretched out together, arms glued to my body. Like in a coffin. And I stopped breathing for a while. She began, I turned my eyes up to the ceiling. White, a blank sheet two yards above us. She asked me if I wanted slow or faster, I couldn't sense, told her a bit slower. It felt as though an alien member was stuck to my body. An alien member coming out of my body. Back to front, like cleaning the barrel of a gun. Front to back, now slower somewhat. Her breasts were pressing forward. She was looking down at her hand, waiting attentively. I could feel it was squeezing me and then opening and relaxing. . . the hard body on me. For a moment you don't look anywhere, just feel, the body fills out, saliva starting in the mouth, the animal scratches inside and wants to get out, you want to get out, the animal thirsty pushes inside to exit your mind overflowing. Overflowing between her fingers and surging and you move toward her breasts. And then, then as if you didn't exist, as if the animal died and me that I came wholly inside her. If I could stay like this, empty, empty and clean. (p. 99)

This passage suggests an experience of female ravishment, of the male body submitting to and then rising toward a "hard body" that simultaneously pleasures and masters it, that arouses and expels an indwelling animal that, like a succubus, strains for release and final purgation. The description echoes that of Section V of The First Death ("I swell with lust, unhallowed I rise, in the recesses of your body I spill my blood"), but here the act of coition leads not, as in the former passage, to a final sense of "Despair," but to one of futurity, of possibility, in which the woman may be returned to and the liberating cycle resumed (p. 101). 
We are still, at this point, far from a properly human relationship, let alone the larger one of community. The speaker of the passage doesn't have a name, though it's unclear whether he can't recall it or simply never had one. The woman he's with is similarly unidentified. Their relationship is one of sexual conjunction, which is to say, an animal function. They do, however, share speech, and the scene around them is urban and even fastidiously civilized ("Trousers carefully on the chair"). What transpires between them on the essential level, at least for the male, is the expulsion of a primal animality that creates the space for a possible humanity, a death unto life. The critical passage is, as so often in Lyacos, grammatically indeterminate: "And then, then as if you didn't exist, as if the animal died and me that I came wholly inside her." From "you" to "me" to "I" suggests an identity coming into finally possibility through a violent ontological passage. The "animal" in the speaker does not die, nor is it permanently expelled, for we cannot physically exist without it as a component of our being. It is, rather, set aside so that another space can be cleared within the speaker, the space for a person.

I take this scene to be particularly critical in the poem, because it suggests its process as a passage, by no means guaranteed or identifiable with a progress toward civilization, but rather as a constant toil, now advancing and now retreating. Lyacos suggests this a bit further on in Z213 in the image of a "burnt out Lighthouse" (the capitalization is significant) that opens up on the prospect of a terminally decayed world:

your cities exhausted, the aged

children, the aching teeth of desire, the carriages full of

the drowned, the truth that tightens, around what

happened it tightens,

you say it, they gather together, a circle, the gallows, the

trees,

the fruit that does not fall on the ground, the bodies that

broke from affection,

the friend you don't see and don't hear ... (p. 107)

In this densely concentrated passage, Lyacos depicts a condition that seems to have gone beyond hope, in which desire begets only aged children; a carriage - the image of passage — carries only the dead; truth has hardened into dogma; trees bear but, Tantalus-like, do not yield their fruit; bodies conjoin but no longer affirm; friendship is recalled but no longer attainable. In the center of the passage is a circle, a symbol of gathering and community that immediately assumes the grotesque form of a noose that, aligned with the "trees" that bear the fruit that does not fall—-the bodies, perhaps, of the hanged?

This is the saeculum, the order of the world that cannot be its own salvation. We are once again within Lyacos' synoptic vision of Scripture, one that does not separate the two Testaments but engages them as a continuous dialogue with each other. The Hebrew Testament is the story of an unconsummated pilgrimage, in which a single tribe of people, distinguished from yet symbolic of all humanity, seeks a Promised Land, loses it through iniquity, regains it through renewed exile and struggle, loses it yet again, but never abandons the hope of a definitive return. It is the single most abiding myth of the three great monotheistic religions, whose founding faith has, thus far and against all historical odds, kept it startlingly alive in the modern political world. Lyacos adapts it to his own purposes, and universalizes it as an emblem of the human condition as such. Judaism has no final eschatological dimension; there is no transcendence of history, but the People endure. This connects Judaism with Hellenism, with its implicit notion of the cycle in which the human city waxes and wanes in a perdurable round. We seek, that is, the final accounting which the New Testament promises us as a blessedness beyond time, but we remain in the saeculum, a condition in which hope rises and falls to define itself anew, and names are forgotten only to be reinvented.

In the Hebrew Testament, the most potent symbol of this experience is the Tower of Babel, in which human aspiration exceeds its limits in the hope of provoking a final reckoning through supernal knowledge or empowerment. This hope must necessarily be dashed, and all fall with it; as Lyacos puts it, "And let us be lost, perhaps better for us like that" (Z213, p. 129). As this is a repeated experience on the collective level in the saeculum, so too it is on the personal one. The latter portions of Z213 are preoccupied again with the problematic of individual consciousness. Our inability to fix reality is, as Lyacos points out, a function of our most defining cycle, the biological one that alternates our lives between sleep and waking, memory and loss:

... you sleep, you wake up so many times, so often, you don't know when you are asleep and when you are awake, why be awake, now you may be asleep, what you remember you may remember in sleep, wake up in a dream, remember inside a dream, different memory other things you remember when you are in a dream, you have a different life in the dream, you remember who you are what you did, and even though you may not be the person you were when again you wake up you don't doubt who you are in the dream, even when you are changing and you are changing continuously, you don't wonder, things are naturally so, it is not strange, you are changing continuously, your body, around you, everything everywhere, you are somebody else, but you are the same, you are him. (pp. 131, 133) 
We are both more protean and more believable to ourselves in dream: perpetual transformation seems our lot, and the labor of memory we resume when awake is only the poor substitute for the natural conviction we possess in dream, the sense of both world and self as a condition of flux. Continuity is change, "God reeling up and down landscapes and buildings, knocks down, opens new roads, doesn't like it, changes again" (ibid.). Or so it seems, for what appears change is only the changing face of continuity: "His world is onefold, and you perceive neither seam nor contradiction." This is the secret of divine unity, the unity that belongs to the Being without a name. We may intuit it, but it is not the realm we inhabit, and even if we are "hiding" a true name in the recesses of our own being, one that we hope will truly define it, it is finally only "a name at the end of a series of names" (ibid.). No human understanding prevails, and, even in this world seemingly enclosed by Scriptural vision, "Not even Scripture stands out" (p. 139).

Z213 ends not with this solitude, however, but, in its penultimate scene, with the most primitive assertion of human community, a detailed depiction of the slow butchery of a lamb. The lamb is the symbol of sacrifice par excellence, of course, but there is no sense of ritual here, merely brutal slaughter. The coda to this, a single long sentence that starts without predication, appears to take the perspective of an animal hunted down to sheer exhaustion and surrender. There is no moment of recognition between predator and prey as death (presumably) comes: "you are feeling the blow, you open your mouth, you look at his mouth, you don't want to stand up any more" (p. 147).

We are, perhaps, at a degré zéro here, in which life is reduced to a feeding frenzy in which the distinction between human and animal itself vanishes. If, however, we must begin with the individual as one who fails to remember himself, so, Lyacos suggests, fraternity begins with the simple objectification of the other on the most primitive, even cannibalistic level, as a source of alimentation. It is the labor of each day, individually and collectively, to go beyond this point, even if what is built is only a new Babel.

With this in mind, we may turn our attention to the second volume in the trilogy, With the People from the Bridge. This volume offers us a figure, the Narrator, who suggests a continuous presence although he too lacks a name and does not actually narrate but rather functions as a kind of stage manager and director in the mise-en-scène of the text, assigning other figures their roles and action although nothing approaching drama actually ensues: speaker tenses fade in and out of the first person, and identities only slowly coalesce or persist for long. At the same time, Lyacos exercises a firm mastery of these disparate materials; nothing in them seems arbitrary or wasted, and the sense of atmosphere they build is cumulative and compelling. It is this atmosphere that creates such stability and focus as the poem is willing to entertain, and enables us to consider it as presenting a social image rather than a kaleidoscope of personal extremities.

The unifying symbol of the poem is the bridge, a concrete as well as metaphoric image of passage. As it appears, however, it has no indication of traffic and is perhaps a derelict structure. The people who live by or under it, like any homeless population, are seemingly cut off from any economy beyond scavenging. On the other hand, they are not people under or of the bridge, but from it, which implies more than a transient abode. Perhaps it would be better to suggest that it is a situation, comprised of an indistinct past and an uncertain future, and that the bridge itself is the emblem of a journey with no sure promise of destination or arrival.

The 'people' - thirteen more or less identifiable characters, but also assorted voices and presences that appear among them as revenants - are, like any homeless population, living in primitive conditions, burning fires for warmth and using a cut-down oil drum as a table-cum-altar. But they also have possession of a working television and the cast-off technology of a video cassette, and books and newspapers are occasionally brought in from outside, primarily for fuel. The suggestion is that some kind of modern civilization is still going on outside, but it is also true that past and present seem permeable, as if time had been beaten flat. If there is any privileged context, it is the biblical one, for biblical texts are quoted, paraphrased, or intimated throughout the text, and the Bible is the one book the 'people' do not consider burning. This point d'appui creates the spatiotemporal grid on which the poem rests, enabling Lyacos to move from remote antiquity and folklore through visionary figures such as Dante to the stalled and crumbling enterprise of modernity. If we're never entirely clear where and when we are, it's because we're everywhere at once, among the living and the dead, all copresent in the matrix of the text.

The 'people' who set off on their journey - and the critical Hebraic element here is that of the journey, a progression against all odds but with a destination that, in this world or the next, is not theirs to finally define - have been given a further vision in a Word that leads beyond the Law, but one which clouds as well as clarifies. At its most exalted, the Christian vision had been one of a kingdom of souls, living, dead, and yet to come, all comprehended in the eternal gaze and embrace of God, but torn, too, by the competing empires of Heaven and Hell. The vision, that is, was at once unitary and fluid, and deeply penetrated, as historical Christianity was, by the darker intuitions of folkloric myth, of wandering spirits, of vampires, of unseen presences just beyond the campfire. Christianity had sought to banish or at least domesticate these dead/undead figures, but in its present technobarbaric decay (the narrator with nothing left to narrate, the communicative devices with nothing to communicate), they deeply unsettle us again. A quotation from Mark 5.9 early in the poem reminds us of the task of exorcism faced by early Christianity:

For he said unto him, come out thou unclean spirit from the man, and he asked him; what is thy name? and he answered 
saying; my name is legion

for we are many. (Bridge 13)

What Jesus seeks to expel here is not a single spirit but a figurative host, and it is not clear how he will prevail. The dogs whose barking is invoked throughout the poem are symbolic both of the underworld (Cerberus) and of the animal alertness that detects the presence of the fearful and the uncanny; they are, too, emblematic of the feral creatures of social decay. On one level, indeed, it is possible to read Lyacos' text as a conventionally apocalyptic postmodern one in which meaning is not signified but depleted by broken narrative and repetition. Speech and action are repeatedly broken off, and circumstances seem to grow progressively more dire. Fires will not stay lit; wounds will not heal. Seagulls that swoop to peck at exposed flesh seem to indicate a city under a particularly intimate and malefic siege. But Lyacos' aim is not to depict despair as such. It is rather, in the deeply Christian signification of the poem, to suggest the possibility of redemption. Indeed, Lyacos' fundamental insight is that redemption is dialectically entwined with despair, and that one cannot be called forth without the other. This too is a part of Christian tradition-the dark night of the soul that precedes the moment of grace, of enlightenment and salvation. In Lyacos, however, such a moment is experienced not simply on an individual level, but as a collective crisis in which personality and community are inextricably interwoven, and each person, even in solitude, experiences in and for the whole. Moreover, what 'redemption' means in and for a secular society in the present is very much an open question. The small group of people who live under Lyacos' bridge, largely cut off from contact with an outside world that may only consist of similar, isolated groups, tells us little about what a genuinely sacred community might look like: you might call them pre-Christians living in a post-Christian world, in which there is a book that may not be burnt, but, by the same token, can no longer be read. Is there, then, any 'bridge' between the quest for love between individual persons and the potential agape of a community? Lyacos suggests this, finally, in a latter section of the poem:

They are coming, look at the street,

there are already enough of them

down there, look further back,

you see how many there are?

At the end of the street it is full. Wait a bit.

Do you see them there?

Like a wave that swells as it comes.

Full now. Here, look here.

A great flock splitting left and right.

Each one gets to his door

knows which one.

There is still something in their minds.

You wanted to go and find them.

But they come and find you before that.

Leave the door open for them to come in.

Listen. He is coming up the stairs.

Don't stand up. He is coming.

He came up. He has come.

They have come together. (pp. 38-39)

A "chorus" is speaking here, though the imperative voice appears to be addressing someone in the singular ("Here, look here"). The observer thus indicated sees a great crowd that seems to be forming in procession and then spilling over like a wave, a "flock" that divides at what seems a moment of impact into single individuals for each of whom there is an appointed door he or she finds unerringly. This suggests an enactment of salvation in which the "saved' community, the "flock," is disaggregated at the critical moment so that individual souls may find their destined way before the reunion of beatitude. At the same time, however, the journey is incomplete: there is still a separation, presumably that of the observer, who for his part and in the same instant reaches to join them ("You wanted to go and find them"). But in the divine instant in which act becomes coterminous with desire, the observer himself is discovered before he can reach out.

In the last lines of the passage, the observer is again addressed imperatively ("Listen"), but what he is told to expect is not a throng but only a nameless singularity ("He"), who is indicated as simultaneously on his way and already present ("He is coming. / He came up. He has come."). The three tense instructions indicate the condition of simultaneity, of time as overcome. Yet we are not to make the facile assumption that the "He" indicated here is the singular Savior. The community of the "flock," although it has divided into individuals each of whom has a separate portal, is nonetheless immediately reconstituted ("they" come and seek the observer; it is for them that the door-his door-is to be left open; it is "they" who have, already, found him.) The observer belongs to the flock, which is incomplete without him; there is no kingdom but that all must belong. At the same time, however, there is, as Lyacos says, both a column of cloud and a column of fire, a pillar of many and a pillar of one (Z213, p. 123). 
Poena Damni is, nevertheless, not the poem of a Christian apologist, but of an agnostic thoroughly permeated by the Christian tradition in its deepest sense, and to the folklore - pagan as well as Christian - that has formed around it as part of its historical substance. Whether or not we can or will be saved in any eschatological sense is left unresolved; what Lyacos wants to tell us is that we must all be saved — or save each other-together. Thus, With the People from the Bridge appears to end with its last remaining voice, that of the Narrator, offering the assurance of a resurrection in the flesh:

I will open your graves

and cause you to come up out of your graves

behold I will cause breath to enter into you

and I will lay sinews upon you

and will bring up flesh upon you

and will cover you with skin

and put breath in you

and ye shall live. (p. 60)

On the facing page, however, we read this final text: "The partially decomposed head of a / woman, stolen from a crypt at / Hollywood Memorial Park Cemetery / early Sunday, was found in the street / next up to a man who was subsequently / arrested, Los Angeles police said."

This gruesome tabloid bit serves to bring us back to earth, to the abiding reality of human depravity and the distance that separates the saeculum from salvation. But it is also the poet's reminder that the heavenly company will always be incomplete as long as any member of the human community is left behind, and that the world is the condition of the one who has not been included.

\section{Endnote}

All textual references are to Poena Damni, The First Death (2017); Poena Damni, With the People from the Bridge (2014); Poena Damni, Z213: EXIT [2016], all translated by Shorsha Sullivan in collaboration with the author and published by Shoestring Press (Nottingham, UK). 